DOI: 10.1515/ausp-2015-0011

\title{
Translation and Political Discourse
}

\author{
Mátyás BÁNHEGYI \\ Department of English Linguistics \\ Károli Gáspár University of the Reformed Church in Hungary \\ banhegyi.matyas@kre.hu
}

\begin{abstract}
The paper describes the text linguistic research of political texts in the field of Translation Studies and presents an overview of critical discourse analysis-based studies. First, the relationship between text, power and ideology and its implications on the role of translation are explored. This is followed by a review of a number of studies on the translation of political texts and on the power relations involved. The paper classifies such studies into the following six categories representing distinct research fields: translators' professional roles and politics; translators acting as mediators in situations of political conflict; translators' professional responsibilities and the strategies they apply; the inference of translators' own historical, social and cultural backgrounds; manipulation in the translation of literary texts and other text types; and critical discourse awareness in Translation Studies. The most recent studies in the above research fields and their results are also presented. It is concluded that these approaches exhibit quite varied research methods and their results are almost impossible to compare. With a view to the future development of this research field, it seems expedient to introduce a unified research theory, method and tool.
\end{abstract}

Keywords: Translation Studies, critical discourse analysis, political discourse, ideology, power

\section{Introduction}

In order to provide a description of the features of translation and translated texts, one branch of Translation Studies deals with the analysis of source texts and their corresponding target texts. Apart from describing translation procedures, translation strategies and translation methods (Bednárová-Gibová 2012), Translation Studies has long been intrigued and fascinated by political discourse and as politics is increasingly done in supranational contexts, translation is inevitably part of international negotiations, struggles and political power games. Therefore, apart from monolingual communication, translation in bilingual and 
multilingual contexts plays a vital role in gaining, establishing and maintaining political power and/or exhibiting ideology. This scenario inevitably results in an increased interest in what ways translation contributes to maintaining social power and to creating or reproducing ideology. The related research field in Translation Studies has produced numerous approaches for the description of various features of political texts and offers diverse analytical tools for research. In fact, the way translated texts are used (or misused and even abused) for political purposes has very complex social, psychological and textual implications, which, in our opinion, can and need be studied and described systematically within Translation Studies with the help of the analytical tools offered by Critical Discourse Analysis.

This paper provides an overview of the relationship between political discourse (including texts created through translation), power and ideology, to be followed by a review of Translation Studies specific research in the field of political discourse. Political discourse is interpreted here as a spoken or written act of communication used in formal or non-formal political contexts that relates to, deals with or describes any political event, organisation or actor. As we shall see, the analysis of political discourse within Translation Studies offers numerous approaches and a wide range of analytical methods. This relatively narrow research field will be described in more detail below.

\section{Text, power and ideology}

It is a linguistics commonplace that texts exist in their social context: the understanding of the textual features of any text, including translations, will inevitably involve the creators and the audience of these texts as well as the social and cultural relationships holding between the human interactants involved. Such human relationships will also involve possible unequal statuses between the parties concerned, which will give rise to diverse relations of power. Power is interpreted as the social power of groups or institutions over persons or groups of people, through which the actions or possibilities of action available to such persons or groups can potentially be limited. Such power relations may also be exhibited by texts. Even if power is primarily a social phenomenon (as it exists between humans), language will be a very powerful tool for obtaining and maintaining power in human communicative contexts (Fowler 1985). Once such power relations have been accepted, are taken for granted and are seen as natural in the given socialcultural context, it is possible to talk about an ideology with reference to the social groups involved. Ideology is a composite of the "basic beliefs that underlie the social representations of a social group" (van Dijk 2003: 10), that is, ideology is the set of power relations that ensure the social status of a given social group through reinforcing the social representation of this group in other social groups. 
The literature abounds in the description of the relationship between power and communication. However, as the main focus of the current paper is politics and translation, the present discussion will be narrowed down to one specific human communicative situation and text type: politics and political texts (or political discourse). Political texts in the scope of the present paper are understood as institutionalised means of communication through which political power may be obtained and retained and through which this very power and the related ideology can be maintained. Translation in bi- and multilingual contexts plays a crucial role in retaining such political power and preserving the ideology related to it.

\section{Translation, power and politics}

In recent years, more precisely after the 'cultural turn' of the early 1990s (Bassnett and Lefevere 1990: 12, Dimitriu 2002: 2, Hatim and Munday 2004: 313), Translation Studies has shown intense interest in analysing the translation of political texts as well as the ideology expressed and the power relations involved in the translation of such texts. The main research areas in this field include the following directions, represented mainly by the scholars appearing in parentheses below:

(1) diverse purpose cross sections of discourse analysis, translation studies and politics (Hatim and Mason 1990, Chilton and Schäffner 2002, Schäffner 2004, Bánhegyi 2008, Bánhegyi 2009);

(2) the analysis of the social, cultural, ideological and political contexts of source and target texts and cultures (Pym 1992 and 2000; Schäffner 2003);

(3) text typology and textual functions of source and target language texts (Nord 1997, Trosborg 1997);

(4) the role of translators as intercultural agents or cultural mediators (Venuti 1992, Katan 1999, Doorslaer 2010);

(5) translators being potential points of conflict during their work (Tymoczko and Gentzler 2002, Tymoczko 2003);

(6) translators' purposeful manipulation of target texts and translators' textual choices reflecting ideological and/or political commitment (Álvarez and Vidal 1996, Baker 2006, Conway and Vaskivska 2010); and, recently,

(7) translators' political activism and social activism as part of their professional work (Tymoczko 2006, Baker 2007).

Apart from the field dealing with the cross section of discourse analysis, translation studies and politics, most of the above research directions do not use specific text linguistic approaches to support their text-related claims. Nor do they use textual evidence quoted from the texts under scrutiny in their larger social context to pinpoint and interpret textual differences between source 
and target language texts as part of their respective research methodology and analysis. Such approaches and their results often seem unconvincing, even perhaps methodologically inappropriate and ad hoc: if there is no systematic methodology or a theoretically well-grounded foundation of analysis with sufficient objectivity, i.e. if analysts (intuitively) pick a few expressions of their choice from the source and target texts and add some (subjective) personal comments as explanation, then the resulting analysis cannot be deemed as valid or reliable as it lacks a proper methodology, reliable theoretical foundations and a required level of objectivity.

Not denying the merits of any of these research directions (e.g. facilitation theory formulation), we often find that some of the resulting data are based on explanatory details and ad hoc descriptions of contexts rather than on a systematic analysis of hard textual data. In our view, data that can be deemed objective will be obtained the most reliably with the help of text linguistic approaches. Based on this assumption, in the next section we will describe which text linguistic approaches are present in today's trends of critical linguistics and in the field of Translation Studies concerning the analysis of political discourse.

\subsection{Research on the translation of political discourse}

After the above short introduction to the analysis of the translation of political discourse and the power relations displayed by such texts, the current section focuses on political discourse oriented translation research using text linguistic approaches. For terminological precision, it must be noted that in Translation Studies political discourse is also termed discourse in situations of conflict (Salama-Carr 2007). In our interpretation, translation research involving political discourse can be classified into seven distinct research fields as far as research topics are concerned. These seven research fields and their representatives are the following:

1. Translators' professional roles and politics: Palmer (2007), Dragovic-Drouet's (2007), Gagnon (2006);

2. Translators acting as mediators in situations of political conflict: Tang (2007), Calzada Pérez (2007);

3. Translators' professional responsibilities and the strategies they apply: Maier (2007), Schäffner (1998), Hernández Guerrero (2010);

4. The inference of translators' own historical, social and cultural backgrounds: Kuhiwczak (2007), Nikolaou (2007);

5. Manipulation in the translation of literary texts and other text types: Foster (2007), Williams (2007), Chadwick (2007), Baker (2006);

6. Critical discourse awareness in translation: Valdeón (2007), Chan (2007), Schäffner (2004). 
Below, these research areas will be introduced and their main findings will be summarised to show that Translation Studies does not yet have a commonly accepted and systematic analytical tool for the examination of political texts. Depending on the nature of the research in question and on the theme of politics involved, diverse researchers apply a very wide range of analytical tools, which makes the advances of translation research on politics very difficult to compare and systematise. This, in turn, also causes the fragmentation of research efforts.

\subsubsection{Translators' professional roles and politics}

With the internationalisation of politics, translators' professional roles and divided loyalties have been foregrounded by Translation Studies. Palmer (2007) deals with the different roles Iraqi people working for Western media assume and the political commitment-induced conflicting loyalties such a situation poses to these translators. Relying on Wadensjö's (1998) Conduit Theory, Palmer traces media reporters' and translators' roles in the flow of information about the Iraqi situation of conflict. Palmer concludes that, even if such translators are trusted by Western media people working in the area, misinformation may happen as a result of (1) translators' providing summaries rather than word-byword translations, (2) omissions of textual material considered irrelevant by the translator, (3) journalists' linguistic inability to mingle in the local community and the resulting incapacity to understand the local culture, and finally (4) as a result of translators' biased social embeddedness, social status and non-neutral contacts in the local community in question. With reference to source and target texts, Palmer considers different cultural and political backgrounds as a potential source of conflicting political orientations exhibited by these texts.

Dragovic-Drouet's (2007) starting point in her discussion of translations related to the Yugoslavian conflict is neutrality as interpreted by Seleskovitch (1983) as well as the Newmarkian (1989) criteria of moral and factual truth. Through a textual analysis of source and target language texts of the Yugoslavian conflict, Dragovic-Drouet aims to prove that the above-mentioned professional standards are oftentimes not observed by translators and that translators may resort to censoring or modifying texts should they perceive that, in their judgement, primary text producers (reporters, media personnel, etc.) show unwanted embeddedness (cultural bias), which potentially results in unfair communication. Turning to translation methodology, Dragovic-Drouet claims that translator training should develop in future translators the ability of coping with situations of conflict both linguistically and in terms of terminology management. This study reveals that translators can potentially manipulate texts politically and also sheds light on the issue of awareness-raising in connection with the translation of political texts. 
Gagnon (2006) describes the ways official translations are handled and performed in Canada by the Canadian Prime Minister's Office, the Parliament and other government institutions and explores how such translations are received. With reference to the status of originals and translations, Gagnon, discussing the hybridity of target texts (texts showing unusual, strange textual features in the target culture as a result of conscious, deliberate translator decisions), concludes that translations have a lower status than originals in Canada. In terms of the adaptation of texts and the reception of French and English parallel texts, Gagnon, relying on textual analysis performed by way of Fairclough's (1989) Critical Discourse Analysis Model, claims that the way translations are done, i.e. what institutional translation strategies are applied, are decided by the audience to be convinced. This signals that the actual ideological aims will determine the translation strategies applied. This points towards the assumption that "Frenchand English-Canadian cultures do not often meet in translated federal speeches" (Gagnon 2006: 84), which is contrary to the expectations of a homogeneous Canadian nation. This statement seems to indicate that it is almost impossible (and probably at some points not even desired) to produce politically equivalent texts even in the case of bilingual countries, let alone other, more diverse political contexts (e.g. texts used at international levels).

The studies described above illustrate that the analysis of the translation of political texts must definitely extend to the contemporary national and/or international contexts the text under scrutiny have been created in.

\subsubsection{Translators acting as mediators in situations of political conflict}

As politics is becoming an increasingly international activity, translators often find themselves in the role of mediators in political conflict. Tang (2007) focuses on cross-cultural conflicts surfacing as either cultural, social or ideological conflicts. Tang, on the basis of LeBaron's (2003) Theory of Cultural Conflicts, argues that cross-cultural conflicts can be subdivided into soft and hard conflicts on the basis of their scope, i.e. suppression or open voicing of conflict by the society (societies) involved. If discussion about such conflicts is suppressed, we talk about soft conflicts, while in case conflicts are openly addressed, we encounter hard conflicts. With reference to translation from English into Chinese and vice versa, Tang sees translators "sandwiched between Chinese and Western cultures" (Tang 2007: 139), and, through the culturally contextualised close reading of the English translation of Chinese texts, concludes that translators actually tend to eliminate soft conflicts. Given this, Tang calls for translators' sensitisation to conflicts so that they will be able to cope with hard conflicts on an international scale in a more effective manner. This suggests that awareness-raising should be a component of translation training, for which even more extensive research is necessary. 
Calzada Pérez (2007) explores translators' roles in situations of conflict and urges that translators tackle situations of conflicts rather than avoid them. The starting point of the discussion is that advertising is in fact a "site of ideological conflict(s)" (Calzada Pérez 2007: 149), and that advertisements can cause or settle conflicts. In this context, translators, relying on their cross-cultural skills, abilities and strategies, may become "ideal conflict mediators" (Calzada Pérez 2007: 149). Relying on Cronin's (2003) categorisation of censorship and zero translation and connecting this categorisation with possible translation strategies, Calzada Pérez concludes that translators, as text producers, may easily reach and create points of problem settlement with the help of their translations through "focusing on consensus" (Calzada Pérez 2007: 156), or can modify disagreements to "achieve long-lasting benefits" (Calzada Pérez 2007: 156). These findings suggest that translators can also interfere in politics.

The studies presented in this section show that the translators of political texts are often in the "frontline": the features and the quality of their work will influence both the reception of their texts and the political events associated with such texts. Therefore, the analysis of political texts by researchers must extend to the reception and, if possible, the political events directly or closely connected to the translated text.

\subsubsection{Translators' professional responsibilities and translation strategies}

The professional responsibilities translators take and the strategies they apply when translating political texts have also been researched in Translation Studies. In connection with professional responsibilities, Maier (2007) claims that even if translators have recently acquired a higher status in terms of their usefulness and visibility as compared to earlier times, they concurrently fail to recognise the need to discuss their responsibilities and to learn to account for their work in situations of conflict. In Maier's interpretation, translators can act as intersections between two opposing sides or can function as points of resistance and conflict. Maier claims that even today some translators are insensitive to perceiving situations of conflict, and argues that translators actually face internal conflicts (conflicts within the translator) when exposed to translating texts of conflict situations. In addition, Maier calls for an exploration and a deeper understanding of the diverse situations of conflict today's translators might encounter during their work, and designates this as a further field of (possibly job ethical) research. In this respect, Maier's study touches upon the relationship between job ethics and the translation of political texts as reflected by target texts.

Schäffner (1998) explores different types of hedges in European political discourse. Relying on Lakoff's (1973) definition, Schäffner defines hedges as words whose meaning involves “vagueness, indeterminateness” (Schäffner 1998: 
185) with reference to the phrase they modify. Schäffner establishes five types of hedges: evidentiality hedges such as I think, it seems, which refer to the speaker's degree of commitment to the truth expressed in a text; modifying hedges such as fairly, too, typical, which "shift the scope of indeterminateness of the utterances" (Schäffner 1998: 191); quantifying hedges such as in every respect, in some respect, which "relate to characteristics of the whole scope of precision" (Schäffner 1998: 191); despecifying hedges such as kind of, roughly, which "extend the scope of indeterminateness" (Schäffner 1998: 192); and specifying hedges such as real, genuine, true, exactly, which "narrow down the scope of indeterminateness of a concept or a proposition" (Schäffner 1998: 193). Based on comparative pragmatic textual analysis, Schäffner concludes that source text hedges can be rendered as the same type of hedges in the target language, as different type of hedges causing shifts in the target text, can be deleted and even new hedges can be added in the target text. Politically contextualising the examples, Schäffner explains the effects such hedges have on the receivers of the translated texts. Schäffner concludes by noting the semantic and pragmatic problems hedges can cause to translators and calls for a more systematic description of hedging devices. This suggests that microlevel textual features must be taken into consideration in the analysis of the translation of political texts.

Hernández Guerrero (2010) studies originally foreign language interviews published in Spanish in the Spanish newspaper El Mundo and discusses in what ways such interviews, which are created through a rewriting process, are adjusted to the needs and expectations of the local readership. In addition, the paper focuses on the translation strategies applied to this end. Based on Stetting's (1989) noting of transedition, the study explores to what extent the job of translation at a news agency entails translation and editing. In the scope of this, textual changes in target texts are qualified as modification, addition or omission, clarity enhancement, reorganisation for editorial purposes and changes suited to textual conventions. These textual alterations are analysed quantitatively and qualitatively and it is concluded that newsworthiness is the most important criterion these translated texts must primarily satisfy. Thus, fidelity to the source text is pushed to the background and faithfulness to the target audience is foregrounded in the scope of localising the target text. It is also claimed that numerous instances of recontextualisation are effected in the target text, which may increase the text's potential to influence and manipulate its readers.

The above studies show that research must extend to the realisations of certain recurrent translation strategies surfacing in translated political texts and their pragmatic effects. This is justified by the claim that conclusions established on the basis of one-off or non-contextualised microtextual textual instances may produce misleading research results. 


\subsubsection{The inference of translators' own historical and cultural backgrounds}

Translators' historical and cultural backgrounds can also interfere with the translation of political texts. Translators' historical and cultural backgrounds, through their interpretation of the events, actors, etc. described in the target text, shape readers' understanding of, and attitude to, historical events through the translators' interpretation of events surfacing in target texts. In his study, Kuhiwczak (2007) attempts to show how, during the transition from oral to written Holocaust history, the translation of originally non-English oral sources into written English historical records published as English translations, altered the text type and tone of such primary historical sources. Kuhiwczak goes as far as theoretically questioning whether translation, at a universal scale, is capable of (precisely) communicating others' thoughts. This suggests that translators' interpretation of the texts for translation plays a crucial role in producing the finalised target text.

Nikolaou (2007), with the help of a comparative textual analysis, examines how Christopher Logue's own personality and his life experiences contributed to his creative translation of Homer's Iliad. Nikolaou claims that, as an artefact, Logue's own literary piece, War Music is in fact the result of the act of translating Iliad and that Logue's views of the situations of conflicts of Iliad evolve through a hermeneutical dialogue between the text to be translated and the translator. Apparently, interpretation, with reference to both source and target texts, plays a vital role in the translation of political texts.

In the light of the above, it may justifiably be claimed that any reliable and valid textual analysis must allow for the exploration of the translators' own political commitment and political attitudes as traceable in translated texts.

\subsubsection{Manipulation in the translation of literary texts and other text types}

Manipulation in the translation of political texts has also developed into a prolific research area. Williams (2007) describes $19^{\text {th }}$ century contemporary GermanEnglish national rivalry and compares biographical details of Wordsworth and his German translator, Freiligrath to reveal textual realisations of such rivalry. Apart from the textual analysis of Freiligrath's translational practice (i.e. the translation of poems, including metre, imagery, etc.), Williams investigates Freiligrath's selection procedure of choosing Wordsworth's politically-charged poems for translation, and the effects contemporary German-English national rivalry and hostility had on the German reception of Wordsworth's poetry. It is concluded that interpretation is only possible in the light of contemporary historical and cultural contexts.

Baker (2006) provides an integrative, fully developed framework for the analysis of political discourse. Due to the complexity of this approach, this framework will 
be described in a more detailed way below. This model can serve as a resource of the description of potential textual features translated political texts may display. In fact, Baker restricts her approach practically to narratives only and does not rely as heavily on text linguistic findings as it would be desirable.

Baker's approach is multidisciplinary in nature and is based on several theories. Its starting point is the premise that political conflicts and the resolution of such conflicts in today's globalised world, as a rule, stretch over national boundaries and thus inevitably involve translation and interpretation activities. According to Baker, power is present exclusively in situations in which a party or parties are forced to act contrary to their wills and interests. Conflicts, Baker (2006: 1) asserts, evolve when parties of opposing interests intend to "undermine each other because they have incompatible goals, competing interests, or fundamentally different values".

By integrating a theory of narrative types, a theory of the assessment of the effectiveness of such narratives, and theories of translators' attitudes towards consenting to or denying the reproduction of ideological contents in texts, Baker wishes to demonstrate that translation itself can either function as a tool in the hands of political elites by creating one single (and consequently one-sided) truth and reality and can therefore enforce a given social and political order on citizens or, quite the contrary, translation can be used as a tool for fighting against such manipulation and corruption of texts.

Baker intends to provide a framework for exploring how translators, through text production, contribute to the creation and promotion of politically-charged narratives, to the wide dissemination of such narratives or to the resistance to the production and dissemination of these narratives. By adopting a standpoint assumed in social and communication theory, Baker (2006: 3) defines narrative (or story) as a linguistic realisation of sequential events of "everyday stories we live by" and later, relying on Fisher's (1987) claim of all human communication essentially being a narrative, extends her definition to incorporate practically every type of discourse. This broad definition allows for the investigation of several genres of discourse in a very diverse range of media.

As far as the possibilities for manipulating narratives in the translation process are concerned, Baker, on the basis of Somers and Gibson (1994), describes four techniques through which the reception of narratives can be influenced. Temporality, relationality, causal emplotment and selective appropriation are all factors impacting the reception of narratives. Such instances of manipulation are common in mediatised communication and in translations transmitted by the mass media. Below, the four techniques established by Baker will be explored in more detail.

Not necessarily portraying a true-to-life sequencing of events, temporality is the subjective, person-specific interpretation and ordering of the sequences of events contained in a narrative. Such a narrative is created through an individual's 
perception of the events included in the given narrative. It is the temporality of narratives that allows translators to interpret the textual material and the logical implications contained in the text. An alteration of the sequencing of events, for instance as a result of translation, can have different implications in the target language text from those surfacing in the source text.

Relationality refers to the interrelatedness of events within a narrative: events have to constitute one single narrative (the narrated events must make up one narrative logically and thematically). Furthermore, the interpretation of every event of a certain narrative is exclusively possible in the light of other events of the given narrative as a whole. Translation is of key importance here as, for instance, the choice of certain lexical items in the target language text can trigger associations of certain narratives, which are possibly different from the narrative associations of the source language community. This feature seems easy to be utilised for political reasons (e.g. for war propaganda) in case well-selected lexis is used that evokes references to well-established public narratives of political agendas.

Carrying also ethical implications, causal emplotment entails the significance of events in narratives, and is connected to the fact that narratives do not merely list events but "weight and explain" them (Baker 2006: 67) in terms of the interpretation and evaluation of events, motifs, etc., thus providing a moral reading of the narrative. Through translation, the weighting of events can be changed to produce deliberately altered patterns of causal emplotment in the target language text.

The last factor in Baker's theory affecting the reception of narratives, selective appropriation, denotes the conscious or subconscious processes during the creation of a narrative through which certain events get included whereas others get excluded from the final version of the narrative. This, in the large scale, in terms of translation, extends to the choices of what narratives of the source culture (i.e. narratives about which events) get translated. This selection, in the hands of politics and journalists, etc. acting as political actors, might easily contribute to the creation of false images or, in worse cases, to the creation of enemy cultures through acts of deliberate appropriation, i.e. purposeful selection of events along certain ideologies or political purposes (cf. selective appropriation above). Baker's approach is revealing and exemplary in a way that is shows that power, ideology and politics related translation research must be multidisciplinary and based on interrelated theories.

Furthermore, with reference to the reception of narratives, Baker identifies translation as an act involving possible alterations in the features of the resulting target text: the aim of altering certain features of target texts can be to renegotiate the features of a given narrative "to produce a politically charged narrative in the target context" (Baker 2006: 105). This can function as a means of constructing a modified, influenced reality for receptors through "strategic moves that are 
consciously initiated in order to present a [social, political or other] movement or a particular position within a certain perspective" (Baker 2006: 106). Baker terms this practice framing.

Baker explores four different ways of framing selecting from among the practically endless methods available and describes the potential uses of such means in translation. The first method of framing is termed temporal and spatial framing and involves no alterations in the text for translation itself but achieves its effect by the careful selection of a suitable text for translation and by embedding such a text "in a temporal and spatial context that accentuates the narrative it depicts and encourages receptors to establish links between it and current narratives" (Baker 2006: 112). This practice is capable of exerting political influence despite the fact that the events of the narrative of the source text may actually be contained within an absolutely different temporal and spatial setting.

An especially common way of framing that appears in connection with the translation of literary pieces is selective appropriation of textual material, which also has possible political implications. In this case, omissions from or additions to the original text are effected in order to "suppress, accentuate or elaborate particular aspects of a narrative encoded in the source text or utterance, or aspects of the larger narrative(s) in which it [the given narrative] is embedded" (Baker 2006: 114). On the translator's side, this act can happen either consciously or unconsciously and may well serve political purposes.

Another way of framing is by labelling. Labelling in this context denotes the practice of using "a lexical item, term or phrase to identify a person, place, group, event or any other key element in a narrative” (Baker 2006: 122), given that such names embody particular viewpoints, beliefs or political commitments of a community.

The fourth method of framing is termed repositioning of participants. This denotes rearranging the hierarchical positions of the characters of the narrative and the receptors of the narrative through altering partly the socio-linguistic features of the participants' speech and partly other features used for such participants' linguistic identification and characterisation. This also creates space for political manipulation through translation.

As a summary, it can be concluded that Baker's theoretical framework takes account of several contextual and intertextual features as well as discusses several instances and means of (possible) political manipulation. However, it does not rely on theories to pinpoint exact textual realisations of such instances of manipulation. Baker rather explains textual phenomena in their social, cultural and political context. We are of the opinion that for the sake of objectivity the analysis of political manipulation in translated texts must include the precise and objective pinpointing of textual elements capable of manipulation, rather than providing solely the social, cultural and political contexts of these texts as a mere backdrop. 
Using an approach quite different from the above and relying on examples from international politics, Schäffner (2001), in the context of international translation practice, explores the ways hybrid texts come about through the translation process. Hybrid texts are the result of conscious, deliberate decisions on the part of the translator: these texts show unusual, strange textual features in the target culture and yet fulfil their intended purpose in the communicative situation in which they exist. The reason for this strangeness of target texts is that the genre of the source text does not exist in the target culture and, consequently, there are no model texts that could guide translators. With reference to political discourse, Schäffner notes that one reason why hybrid texts can come about is globalisation, as internationalisation potentially facilitates the dissemination of source genres (possibly unknown) in target language cultures. Through the use of contrastive text typological analysis, it is concluded that hybrid texts often display textual features that clash with the existing norms in the target language. This could possibly allow for the introduction of socially unaccepted/unacceptable concepts in the target culture and thus play a role in power games and political persuasion.

Based on the studies detailed above, it can be concluded that translation can purposefully be used for political manipulation. With a view to this, the analysis of any translated text must extend to contemporary social, cultural, political and ideological features as well as to the textual realisation and the context-based interpretation of such features.

\subsubsection{Critical discourse awareness in Translation Studies}

Initiatives of critical discourse awareness are identifiable in Translation Studies. This research approach was motivated by the internationalisation of politics, which resulted in an increased number of translated political texts, accessible in diverse channels of the mass media. Once it has been theorised and later proven (e.g. Baker 2006) that source and target texts are not always equivalent in a political sense, and that target texts may be designed to realise partly different communication aims from those of the source text, an even growing concern started to surround the translation of political texts.

Related text linguistic research aimed to point out textually where and in what ways source and target language political texts were not equivalent. The ensuing ethical, political and professional need to critically relate to translated texts, translation activities and the pragmatic effects of translation activities has given rise to numerous critical approaches. In what follows, some of these approaches will be described in greater detail.

Relying on the theories of the best-known and best-established scholars of Critical Discourse Analysis and ideology (Fairclough [1989, 1995], van Dijk [1990, 2003]) as well as of media discourse analysis (Bell [1991, 1998], Schelesinger and 
Lumley [1985]), Valdeón (2007) compares written news reports aired on BBC and CNN and their translations. With ideology interpreted in this context as "a set of assumptions accepted by the participant in a given stretch of discourse" (Valdeón 2007: 101), Valdeón distinguishes two types of mediation with respect to media text producers: positive mediation, i.e. neutrality of text producers towards their subject and negative mediation, i.e. "importing external agendas that might stem from their [the text producers'] own ideological background" (Valdeón 2007: 103). Valdeón, with reference to Baker's (1992) classification of non-equivalence at word level, examines the use and meaning of the lexical items of "terrorist" and "separatist" as well as their (alleged) equivalents. The conclusion of the discussion is that translations produced both for BBC and CNN on the Madrid terrorist attack in 2005 do not seem to "operate in the interest of the target culture, quite the contrary, they operate in their own interest, whether that is understood as personal, editorial or national" (Valdeón 2007: 116). It may be claimed that Valdeón using Baker's taxonomy, manages to reveal instances of word-level manipulation.

Chan (2007) compares the two Chinese versions of Hillary Clinton's Living History published by Chinese publishers China Times and Yilin Press. Chan contextualises the two Chinese versions in the different receiving Chinese cultures and, with the help of close reading, reveals numerous differences between the two translations. The differences between the source text and the two different translations in terms of the Chinese title of the work, certain textual omissions and the translation shifts identified are due to market considerations as well as the influence of Chinese censorship activities. Chan's study perfectly exemplifies that in the case of political texts textual features must be accounted for in the backdrop of the receiving culture.

Schäffner (2004) in the framework of a theoretical proposal urges the closer cooperation of political discourse analysis (PDA) and Translation Studies. PDA explores the link between linguistic behaviour and politics in the fields of pragmatics, semantics and syntax and tries to explain in what ways such linguistic features contribute to political persuasion (cf. Chilton and Schäffner 1997). In the scope of political texts, Schäffner reviews the most common research areas in Translation Studies and establishes the following themes as possible joint research areas of PDA and Translation Studies: research of lexical choice in the target text in comparison with that of the source text, the practice of selecting information to translate, creating new political identities by phrasing and framing (i.e. influencing readers to associate certain phrases with given social and ideological contexts). Through examples, it is demonstrated that all of these translational practices can be used for manipulative purposes, thus sensitivity to such features in the receivers of political texts is very crucial in the case of the translation of political texts. 
In the same study, Schäffner calls for a systematic approach to the research of the translation of political texts and urges the following: 1) the status of translations (overt or covert translation, i.e. is the target text identified as translation or not?) and the general practice of performing such translation work should be established before effecting any kind of analysis, 2) translated texts under scrutiny should be published in the original languages not only in English for the sake of clarity, 3) mistranslations or instances of translation shifts or losses should be analysed in their social-political context so that such shifts can possibly reveal ideological structures (i.e. socially accepted ideology) and 4) that the entire translation process, not only the end-product, should be reviewed in the scope of analyses.

Schäffner, relying on the findings of PDA and with a view to the political strategic functions of political discourse established by PDA, discusses the following four political strategies translation can serve or support when it comes to the rendering of political texts: coercion, resistance, dissimulation as well as legitimisation and delegitimisation. Putting this in perspective in her study, the following is claimed: translation can be used as a means of controlling access to information by carefully selecting texts for translation (coercion). Translators can take an active role and select texts for translation and, by making such texts available to the public, they can make voices other than the official one heard (resistance). Furthermore, a manipulative translation strategy in the hands of those commissioning translations could be either disallowing certain texts to be translated, purposefully commissioning only certain extracts of given texts to be translated or deliberately publishing inaccurate translations: this is collectively termed dissimulation. All of these strategies can prevent persons from receiving non-biased information through translation. Finally, positive self-presentation and the negative presentation of others can be effected as the fourth type of translation strategy termed legitimisation and delegitimisation.

With reference to the possible cooperation of PDA and Translation Studies, it may be stated in general that this approach stresses that word-level equivalence should be assessed and analysed in the ideological context of the source and target cultures; lexical choice in the target text must be analysed within the framework of the target culture; the selection of information to be translated should be interpreted with a view to the most powerful ideology of the source and target cultures; and the creation of new political identities through lexical choice and framing should be contextualised in the target culture.

As the above studies in this section have demonstrated, critical approaches to the translation of political texts must extend to the analysis of lexical-level manipulation, to the comparison of cultural aspects of source and target cultures as well as to the analysis of linguistic choices (possibly) responsible for political and/or ideological manipulation. 


\section{Conclusions}

Based on the studies described in this article, it can be concluded and claimed that the Translation Studies focused analysis of political discourse offers numerous diverse approaches and a wide range of methodologies. This is so much true that the research methods and research results are hardly comparable with one another, and this hinders rapid scientific advancement in this field. To combat this problem, the development and introduction of a more unified approach and research methodology seem desirable. Such an approach and methodology should involve social, political, cultural, historical, hermeneutical and political mass communication contextual features and their interpretation as much and/ or relevant as possible. This may eventually ensure that all contextual features of the creation of political texts, the features and the mediatised use of the translation of such texts, as well as the interplay of these features be described and analysed within the scope of one single theory, research method and tool. The actual development, description and testing of such a theory, method and tool are to be accomplished in the future.

\section{References}

Álvarez, Román and Vidal, M. Carmen-África (eds.). 1996. Translation, Power, Subversion. Clevedon: Multilingual Matters.

Baker, Mona. 1992. In Other Words. London and New York: Routledge.

Baker, Mona. 2006. Translation and Conflict. A Narrative Account. London and New York: Routledge.

Baker, Mona. 2007. Activist Communities of Translators and Interpreters. Paper presented at Translation, Interpreting and Social Activism $1^{\text {st }}$ International Forum. Granada: University of Granada.

Bánhegyi, Mátyás. 2009. The translator's ideology and the reproduction of superstructure. Working Papers in Language Pedagogy 3: 28-56.

Bánhegyi, Mátyás. 2008. A Translation Studies oriented integrative approach to Canadian Political Discourse. Across Languages and Cultures 9(1): 11-107.

Bassnett, Susan. \& Lefevere, André (eds.) 1990. Translation, History and Culture. London: Pinter.

Bednárová-Gibová, Klaudia. 2012. Non-Literary and Literary Text in Translation. Presov: Filozoficka fakulta Presovskej univerzity.

Bell, Allan. 1991. The Language of News Media. Oxford: Blackwell.

Bell, Allan. 1998. The Discourse Structure of News Stories. In Bell, Allan and Garrett, Peter (eds.), Approaches to Media Discourse, 64-104. Oxford: Blackwell. 
Bell, Allan and Garrett, Peter (eds.). 1998. Approaches to Media Discourse. Oxford: Blackwell Publishers.

Calzada Pérez, Maria. 2007. Translating Conflict Advertising in a Globalised Era. In Salama-Carr, Myriam (ed.), Translating and Interpreting Conflict, 149-165. Amsterdam and New York: Rodopi.

Chadwick, Brian. 2007. A 'hip-hop' Translation of a Poem by the Russian Futurist Poet Velimir Khlebnikov (1885-1922). In Salama-Carr, Myriam (ed.), Translating and Interpreting Conflict, 199-220. Amsterdam and New York: Rodopi.

Chan, Red. 2007. One Nation, Two Translations: China's Censorship of Hillary Clinton’s Memoir. In Salama-Carr, Myriam (ed.), Translating and Interpreting Conflict, 119-131. Amsterdam and New York: Rodopi.

Chilton, Paul and Schäffner, Christina (eds.) 2002. Politics as Text and Talk. Analytic Approaches to Political Discourse. Amsterdam and Philadelphia: Benjamins.

Chilton, Paul and Schäffner, Christina. 1997. Discourse and Politics. In van Dijk, Teun. A. (ed.), Discourse as Social Interaction, 206-230. Thousand Oaks, USA: Sage Publications.

Conway, Kyle and Vaskivska, Tetiana. 2010. Consuming news translation: the New York Times online and the "Kremlin rules" experiment. Across Languages and Cultures 11(2): 233-253.

Cronin, Michael. 2003. Translation and Globalisation. London and New York: Routledge.

van Dijk, Teun A. 1990 [1980]. La noticia como discurso: comprehension, estructura y producción de la información. Barcelona: Paidós.

van Dijk, Teun A. 2003. Ideology and Discourse-A Multidisciplinary Introduction. http://www.discourses.org/download/articles/ (14 March 2014).

Dimitriu, Ilenea. 2002. Translation, Diversity and Power. Current Writing 14(2): i-xiv.

van Doorslaer, Luc. 2010. The double extension of translation in the journalistic field. Across Languages and Cultures 11(2): 175-188.

Dragovic-Drouet, Mila. 2007. The Practice of Translation and Interpreting During the Conflicts in the Former Yugoslavia (1991-1999). In Salama-Carr, Myriam (ed.), Translating and Interpreting Conflict, 29-40. Amsterdam and New York: Rodopi.

Fairclough, Norman. 1989. Language and Power. London and New York: Longman.

Fairclough, Norman. 1995. Critical Discourse Analysis: the Critical Study of Language. London and New York: Longman.

Fisher, Walter. 1987. Human Communication as Narration: Towards a Philosophy of Reason, Value, and Action. Columbia: University of South Carolina Press. 
Foster, Ian. 2007. The Translation of William Le Queux's The Invasion of 1910: What Germany Made of Scaremongering in The Daily Mail. In Salama-Carr, Myriam (ed.), Translating and Interpreting Conflict, 169-182. Amsterdam and New York: Rodopi.

Fowler, Roger. 1985. Power. In van Dijk, Teun A. (ed.), Handbook of Discourse Analysis. Vol. 4: 61-82. London: Academic Press.

Gagnon, Chantal. 2006. Language Plurality as Power Struggle, or: Translating Politics in Canada. Target. 18(1): 69-90.

Hatim, Basil and Mason, Ian. 1990. Discourse and the Translator. London: Longman.

Hatim, Basil and Munday, Jeremy. 2004. Translation: An Advanced Resource Book. London and New York: Routledge.

Hernández Guerrero, María José. 2010. Translated interviews in printed media A case study of the Spanish daily El Mundo. Across Languages and Cultures 11(2): 217-232.

Katan, David. 1999. Translating Cultures: An Introduction for Translators, Interpreters, and Mediators. Manchester: St. Jerome Publishing.

Kuhiwczak, Piotr. 2007. The Grammar of Survival. How Do We Read Holocaust Testimonies? In Salama-Carr, Myriam (ed.), Translating and Interpreting Conflict, 61-73. Amsterdam and New York: Rodopi.

Lakoff, George. 1973. Hedges: A study in meaning criteria and the logic of fuzzy concepts. Journal of Philosophical Logic 2: 458-508.

LeBaron, Michelle. 2003. Bridging Cultural Conflicts: A New Approach for a Changing World. San Francisco: Jossey-Bass.

Maier, Carol. 2007. The Translator's Visibility: the Rights and Responsibilities Thereof. In Salama-Carr, Myriam (ed.), Translating and Interpreting Conflict, 253-266. Amsterdam and New York: Rodopi.

Newmark, Peter. 1989. Introductory Survey. In Picken, Catriona (ed.), The Translator's Handbook. 2nd edition. 1-26. London: ASLIB.

Nikolaou, Paschalis. 2007. The Troy of Always: Translation of Conflict in Christopher Logue's War Music. In Salama-Carr, Myriam (ed.), Translating and Interpreting Conflict, 75-95. Amsterdam and New York: Rodopi.

Nord, Christiane. 1997. Translating as a Purposeful Activity. Functionalist Approaches Explained. Manchester: St Jerome.

Palmer, Jerry. 2007. Interpreting and Translation for Western Media in Iraq. In Salama-Carr, Myriam (ed.), Translating and Interpreting Conflict, 13-28. Amsterdam and New York: Rodopi.

Pym, Anthony. 1992. Translation and Text Transfer - An Essay on the Principles of Intercultural Communication. Frankfurt am Main: Peter Lang. 
Pym, Anthony. 2000. Negotiating the Frontier. Translators and Intercultures in Hispanic History. Manchester: St Jerome Publishing.

Schäffner, Christina. 1998. Hedges in Political Texts: A Translational Perspective. In Hickey, Leo (ed.), The Pragmatics of Translation, 185-202. Clevedon: Multilingual Matters.

Schäffner, Christina. 2003. Third Ways and New Centres - Ideological Unity or Difference? In Calzada-Pérez, Maria (ed.), Apropos of Ideology: Translation Studies on Ideology. Ideologies in Translation Studies, 23-41. Manchester: St Jerome.

Schäffner, Christina. 2004. Political Discourse Analysis from the point of view of Translation Studies. Journal of Language and Politics. 3(1): 117-150.

Schäffner, Christina and Adab, Beverly. 2001. The Idea of the Hybrid Text in Translation: Contact as Conflict. Across Languages and Cultures. 2(2): 167-180. Schelesinger, Philip and Lumley, Bob. 1985. Two Debates on Political Violence and the Mass Media: The Organisation of Intellectual Fields in Britain and Italy. In van Dijk, Teun A. (ed.), Discourse and Communication, New Approaches to the Analysis of Mass Media Discourse and Communication, 324-349. Berlin and New York: Walter de Gruyter.

Seleskovitch, Danica. 1983. Faut-il sauver les langues nationals? Role de la traduction et de l'interprétation. Traduire. 116. 5-6.

Stetting, Karen. 1989. Transediting. A New Term for Coping with the Grey Area between Editing and Translating. In Caie, Graham. et al. (eds.), Proceedings from the Fourth Nordic Conference for English Studies, 371-382. Copenhagen: University of Copenhagen.

Tang, Jun. 2007. Encounters with Cross-cultural Conflicts in Translation. In Salama-Carr, Myriam (ed.), Translating and Interpreting Conflict, 135-147. Amsterdam and New York: Rodopi.

Trosborg, Anna. 1997. Text Typology and Translation. Amsterdam and Philadelphia: Benjamins.

Tymoczko, Maria. 2000. Translation and Political Engagement. The Translator. 6(1): 23-47.

Tymoczko, Maria. 2003. Ideology and the Position of the Translator: In What Sense is a Translator 'in between'? In Calzada-Pérez, Maria (ed.), Apropos of Ideology: Translation Studies on Ideology. Ideologies in Translation Studies, 181-202. Manchester: St Jerome.

Tymoczko, Maria. 2006. Translation: ethics, ideology, action. The Massachusetts Review 47(3): 442-461.

Tymoczko, Maria and Gentzler, Edwin. 2002. Introduction. In Tymoczko, Maria and Gentzler, Edwin (eds.), Translation and Power, i-xxviii. Amherst and Boston: University of Massachusetts Press. 
Valdeón, Roberto A. 2007. Ideological Independence or Negative Mediation: BBC Mundo and CNN en Español's (translated) Reporting of Madrid's Terrorist Attacks. In Salama-Carr, Myriam (ed.), Translating and Interpreting Conflict, 99-118. Amsterdam and New York: Rodopi.

Venuti, Lawrence (ed.). 1992. Rethinking Translation: Discourse, Subjectivity, Ideology. London: Routledge.

Wadensjö, Cecilia. 1998. Interpreting as Interaction. Harlow, Essex: Addison Wesley Longman.

Williams, John. 2007. Ferdinand Freiligrath, William Wordsworth, and the Translation of English Poetry into the Conflicts of Nineteen Century German Nationalism. In Salama-Carr, Myriam (ed.), Translating and Interpreting Conflict, 183-198. Amsterdam and New York: Rodopi. 